\title{
Cannabis and Athletic Performance
}

\author{
Jamie F. Burr ${ }^{1}\left[\right.$. Christian P. Cheung ${ }^{1} \cdot$ Andreas M. Kasper $^{2} \cdot$ Scott H. Gillham ${ }^{2} \cdot$ Graeme L. Close $^{2}$
}

Accepted: 16 June 2021 / Published online: 13 September 2021

(c) The Author(s) 2021

\begin{abstract}
Cannabis is widely used for both recreational and medicinal purposes on a global scale. There is accumulating interest in the use of cannabis and its constituents for athletic recovery, and in some instances, performance. Amidst speculation of potential beneficial applications, the effects of cannabis and its two most abundant constituents, delta-9-tetrahydrocannabinol (THC) and cannabidiol (CBD), remain largely un-investigated. The purpose of this review is to critically evaluate the literature describing the effects of whole cannabis, THC, and CBD, on athletic performance and recovery. While investigations of whole cannabis and THC have generally shown either null or detrimental effects on exercise performance in strength and aerobictype activities, studies of sufficient rigor and validity to conclusively declare ergogenic or ergolytic potential in athletes are lacking. The ability of cannabis and THC to perturb cardiovascular homeostasis warrants further investigation regarding mechanisms by which performance may be affected across different exercise modalities and energetic demands. In contrast to cannabis and THC, CBD has largely been scrutinized for its potential to aid in recovery. The beneficial effects of CBD on sleep quality, pain, and mild traumatic brain injury may be of particular interest to certain athletes. However, research in each of these respective areas has yet to be thoroughly investigated in athletic populations. Elucidating the effects of whole cannabis, THC, and CBD is pertinent for both researchers and practitioners given the widespread use of these products, and their potential to interact with athletes' performance and recovery.
\end{abstract}

\section{Key Points}

Use of cannabis, THC, and CBD by athletes for the purposes of improving performance and recovery is increasingly reported across different sports and levels of competition

Appropriate empirical evidence regarding the effects of cannabis use on sport performance is lacking. Understanding the short- and long-term effects of cannabis and THC on human performance in athletes will require well-controlled, athlete-specific research, with applied performance outcomes

CBD may have some promise for aiding athletes with recovery by improving sleep quality, pain, and mild traumatic brain injury

Jamie F. Burr

burrj@uoguelph.ca

1 Human Health and Nutritional Sciences, University of Guelph, 50 Stone Road E, Guelph, ON N1G2W1, Canada

2 Research Institute for Sport and Exercise Sciences, Liverpool John Moores University, Liverpool, UK

\section{Introduction}

The empirical case for or against cannabis use to aid athletic performance remains tenuous. Despite evidence of long-standing human consumption over the ages [1], scientific investigation into the effects of cannabis has been relatively limited, largely in part to challenges faced to investigate a drug that has a long global history of prohibition and tight regulatory control [2, 3]. Despite cannabis remaining an illicit drug in a majority of countries and holding a place on the World Anti-Doping Agency's (WADA) prohibited substance list, accounts of its use amongst competitive and recreational athletes abound [4-7].

Today, the global use of cannabis and formulations made of its derivatives are progressively more widespread as many nations relax laws around both medical and recreational use. Cannabis has been noted as the second most consumed recreational substance, next to alcohol [8], and with such ubiquity and increasing belief of potential for health benefit, the enticement for uptake and use by athletes is not surprising. While commonly used as a recreational drug outside the context of sport, evidence suggests 
that athletes who use cannabis do so with the intent of enhancing performance (whether this is likely to occur or not), with factors such as sporting background, individual vs. team sport participation, competition level, sex, and demographic background further affecting predispositions to use [4-6]. A recent meta-analysis of 11 studies representing over 46,000 athletes of varying age and ability suggests that $\sim 23 \%$ have used some form of cannabis in the past year [9].

Plants of the Cannabis genus contain over 100 genusspecific molecules [10], known as phytocannabinoids: the two most studied being delta-9-tetrahydrocannabinol (THC) and cannabidiol (CBD). THC is widely recognized for its psychotropic effects. The selective breeding and cultivation of new cannabis strains for both recreational and medicinal use has commonly focused on THC, resulting in alterations to cannabinoid ratios and increases in relative THC concentration over time [11]. It is now understood that THC exerts a variety of physiological effects via the endogenous cannabinoid, or endocannabinoid, system. More specifically, THC acts as a partial agonist to the putative endogenous cannabinoid receptors type 1 (CB1) and 2 (CB2), which are located in a wide range of central and peripheral tissues $[12,13]$. CBD, on the other hand, is devoid of psychotropic effects [11], and while it appears to have limited physiological influence through CB1 or CB2, it is believed to act at a number of other receptor targets and may modulate the effects of THC [13-15]. Given the unique effects of THC and CBD to elicit differing physiological effects that could alter exercise performance or recovery, coupled with their differing status as legal or prohibited substances, there is a growing interest in scientific evidence for a variety of purported uses. Furthermore, exercise itself may have unique interactions with the endocannabinoid system which may modulate the effects of exogenous cannabinoids [16]. It is important to acknowledge that cannabis contains many other molecules which could theoretically have physiological effects, and consequently affect human performance; however, the effects of these less abundant cannabinoids and compounds are beyond the scope of this review.

Cannabis is most commonly consumed via inhalation of combusted plant material, colloquially referred to as smoking, which leads to rapid uptake and effects [17]. Cannabinoids may also be consumed by ingesting cannabinoid-containing food products, leading to delayed uptake (30-60 min post) with peak effects occurring between 1.5 and $3 \mathrm{~h}$ postconsumption [18]. It should, however, be acknowledged that the pharmacology of THC and CBD may vary significantly according to a variety of contextual factors, leading to a wide range of bioavailability and elimination rates, as reviewed elsewhere [19]. It is suggested that the effects of consumption, specifically the anxiolytic properties and muscle relaxing effects [4] are a highly sought-after effect for many athletes. Isolated CBD may also possess anxiolytic effects and is purported to have a variety of other beneficial effects such as improvements to sleep, exercise recovery, pain, anxiety, mood, and recovery from concussion [20]. These factors represent motivation for use amongst athletic populations, including professional athletes [20]. Despite the reported widespread use of whole cannabis, cannabinoidbased food products, and isolated CBD amongst athletes who have intentions of affecting athletic performance and/or recovery, there is no clear consensus about the general efficacy of use. At present, according to WADA, cannabis is in contravention of at least two of the three tenets of acceptable use in that it: has potential to enhance sport performance, represents a health risk to athletes, and violates the spirit of sport. Consequently, cannabis and all other cannabinoids (with the exception of CBD) are prohibited during the incompetition phase. Amidst the current evidence this remains a controversial topic in the anti-doping realm [21].

While opinions regarding the efficacy of cannabis (and its constituent products) to meaningfully affect sport performance remain split, cannabis demonstrates clear potential to perturb cardiovascular [22], respiratory [23], and cognitive function [24]. However, in an era of evidence-based decision making, a paucity of trials explicitly examining the effects of whole cannabis, THC and CBD on varied exercise performance and recovery specific outcomes leaves a significant vacuum in which decisions must be made. Notably, rulings about the suitability of use in the context of sport must simultaneously consider both the potential to alter performance and the potential for adverse health effects, which may include serious cardiovascular events, amongst other dangers, which are discussed in detail elsewhere [25-28]. Amongst these issues are the effects that THC may have on alterations in motor control or decision making [29] but in many ways these factors are limited to the psychological, as opposed to psycho-physiological, effects on performance. Thus, this review focuses on the existing evidence for the physiological effects of cannabis, THC, and CBD consumption for exercise performance and recovery, while highlighting requisite areas of future research to progress our empirical understanding in the context of sport performance. Given the notable differences in the psychological and physiological effects of THC and CBD, as well as the potential indications for use in the context of sport, $\mathrm{CBD}$ is discussed independently of whole cannabis and THC.

\section{Cannabis, THC, and Exercise Performance}

The topic of cannabis use and the specific effects of THC on human exercise performance have been considered previously [9, 21, 27, 30-36]. Perplexingly, despite there being 
few new data generated over the past few decades, repeated interpretations of these data have led to vastly different conclusions, with reviews presuming: no benefit $[30,31]$, potential advantages [21] and predominantly an ergolytic effect [9, 32-34]. As such, we include a critical review of current work, and recognition of the knowledge gaps that must be filled to clarify the effect on human performance more specifically.

Compared to the empirical data on other performance related drugs and supplements, the evidence regarding cannabis and THC use is conspicuously lacking. While the volume of data is evidently sparse, it is also noteworthy that the most relevant literature was published 35-45 years ago, with little progress since. Further, there are important considerations of study design and collection methods that limit our ability to meaningfully extrapolate findings for understanding the potential effect of cannabis and THC use on sporting performance in the current day. Amongst these factors are: a substantial increase in the typical dose of THC over time (increased between sixfold and tenfold [11]), evolving methods of consumption and recognition that timing of intake/uptake may influence physiological responses, and an improvement in our ability to quantify performance as physical work output. At the time of writing, we have identified ten studies that consider the effects of cannabis on human performance. Four are cross-sectional studies that characterize the physical capacities of long-term cannabis users compared to non-using controls [37-40], and six involve the administration of cannabis or THC to participants prior to exercise [41-46]. Of these experimental studies, 50\% were performed in persons with identified coronary artery disease or chronic obstructive pulmonary disease (COPD).

\subsection{Chronic Cannabis Users}

Even at a superficial level, there is value in understanding whether individuals who habitually use cannabis differ in their ability to perform exercise from those who do not. Such investigations can shed light on the possibility of persistent performance effects of cannabis with longterm use. However, while such research designs eliminate the need for logistically challenging studies that require the longitudinal administration of dosed cannabis, their crosssectional nature precludes the control of potential bias and cause-and-effect cannot be concluded. Of the existing data comparing cannabis users to non-users, there are no reported differences in aerobic fitness $\left(V^{2 m a x}\right)$, blood pressure, muscular strength and endurance measures, work capacity, and perceived exertion [37-40]. In physically active cannabis users, there are no differences in anaerobic power, or markers of stress and inflammation [37, 39]. Notably, in all studies, participants had been asked to abstain from cannabis consumption for hours to days prior to testing in an attempt to avoid transient physiological effects from recent use, but this might not represent a normal functioning state for heavy users and may be confounded by potential interactions with withdrawal effects [47], which should also be considered in studies where cannabis is administered. The typical concern about the potential for bias (e.g., self-selection to participate) in cross-sectional studies must still be considered. Taken together, there is presently little evidence to suggest chronic cannabis use performed in isolation from training or competition exerts a great effect on any measure of physical performance in recreationally active participants.

\subsection{Diseased}

Exercise is a commonly used tool for the identification and elicitation of signs and symptoms of underlying cardiovascular disease (CVD). While studies examining the combined cardiovascular stress of exercise with cannabis use in persons with identified CVD offer select insight into the human ability to perform aerobic work, their widespread acceptance as concrete evidence of the effects of cannabis or THC on general or high-level human performance is likely misplaced. It is worth highlighting that these studies were never designed to specifically address these questions, and this fact appears to be commonly overlooked in the context of interpretation and application for sport.

The first study of cannabis and exercise was performed in patients $(n=10)$ with significant coronary artery disease ( $>75 \%$ narrowing of coronary artery), with the onset of angina as a major endpoint [42]. Comparing exercise capacity after smoking cannabis or a cigarette placebo, both groups demonstrate a decrease in time to exhaustion. This effect was greater with cannabis use (48\% vs $8.6 \%$ ), possibly because of an increase in myocardial oxygen demand (rate-pressure product), a mechanism discussed in Sect. 3. It is worth noting that, according to the loading protocol described in the methods, even during the control condition participants were capable of only a $25 \mathrm{~W}$ power output and $\leq 25 \%$ of the test was performed at an increased workload of $50 \mathrm{~W}$. For comparison, the modern professional male cyclist can sustain approximately $500 \mathrm{~W}$ for a similar duration of $120 \mathrm{~s}$ amidst hours of riding on consecutive days [48], highlighting the absurdity of using one population to predict effects in the other. The use of cannabis was also a novel stimulus amongst these participants. This work was confirmed by the same group using similarly diseased patients, and an equally low exercise stimulus and THC dosage $(<15 \mathrm{mg})$ the following year [45]. It is worth highlighting that these two studies commonly represent $>50 \%$ of the "performance" evidence cited in existing reviews to suggest an ergolytic effect of cannabis on performance. More recently, to explore the effects on breathlessness and exercise capacity, COPD patients consumed whole cannabis 
(vaporized not smoked, $6.4 \mathrm{mg}$ THC) prior to cardiopulmonary exercise testing [46]. Cannabis was reported to have no impact on any cardiorespiratory responses, nor exercise time, and it is worth noting that exercise lasted $<5 \mathrm{~min}$. Importantly, this group of patients had advanced COPD and fitness that was approximately $10 \%$ of what would be expected for a healthy (non-athletic) control.

\subsection{Healthy}

Steadward and Singh published the first investigation - and to date one of only three studies-in healthy participants $(n=20)$, exploring the effects of cannabis on cardiorespiratory responses to exercise, physical work capacity, and strength [41]. After smoking a moderate dose of THC $(18.2 \mathrm{mg})$, participants showed no apparent effect on handgrip strength, but submaximal work capacity on a cycle ergometer decreased. Importantly, this decrease was concomitant with and inseparable from an increase in submaximal heart rate (HR) in the cannabis group. In papers reporting this research as evidence of an ergolytic effect of cannabis, it is commonly ignored that the test of physical performance, known as the $\mathrm{PWC}_{170}$ - a commonly used test from this time, is a submaximal test for which performance is estimated based on the work output at a given HR (i.e., physical work capacity at a heart rate of $170 \mathrm{bpm}$ ). While the linear relationships between $\mathrm{HR}$ and either $V \mathrm{O}_{2}$ or power output make this a useful measure of capacity under normal circumstances $[49,50]$, this relationship can no longer be trusted as accurate after the administration of a drug that specifically alters the variable that is being controlled for. It should be surprising to no one that when submaximal HR is artificially inflated - and power is measured at a clamped HR - that the work output will necessarily be lower. Notably, there are examples of other definitively ergogenic substances, such as ephedrine and caffeine, that increase submaximal HR and improve endurance performance [51, 52]. Thus, it is inadvisable to conflate the tachycardic effects of cannabis consumption with an ergolytic effect. Avakian et al. [43] similarly followed-up with a submaximal exercise study $\left(40-50 \% V_{2 \max }\right)$ with individuals $(n=6)$, habituated to cannabis use. While no effects of cannabis use were evident on blood pressure, ventilation (VE) or $V_{2}$, a sustained tachycardic HR response was reported. However, no true measures of maximal exercise performance were recorded and the extrapolation of a submaximal effect on HR at $50 \%$ of capacity to exercise performance in a competitive situation requires large, unsupported assumptions of equivalency. Despite the results of this work often being referenced regarding exercise performance, the authors themselves conclude that "....the significance of their observation is not established". Interestingly, all subjects were able to identify the placebo from the low dose $(7.5 \mathrm{mg}) \mathrm{THC}$ condition during exercise, leaving the possibility that psychological factors could modify exercise behaviors, but this has yet to be an empirically tested outcome, nor has blinding been effectively performed. This is an important consideration for future research examining the psycho-physiological effects of cannabis in a more targeted performance setting.

The final, and most specific performance work to date, is the only study to examine healthy participants exercising to maximal capacity. In this work, Renaud and Cormier [44] had participants $(n=12)$ perform progressively more challenging workloads (16.4 W each min) until "leg failure" both under control conditions and after having consumed cannabis (1.7\% THC) dosed at $7 \mathrm{mg}$ of dried cannabis per $\mathrm{kg}$ body weight. At maximal exercise, no differences were found in $\mathrm{HR}, V \mathrm{E}, V \mathrm{O}_{2}$ or volume of exhaled carbon dioxide $\left(\mathrm{VCO}_{2}\right)$; suggesting that despite the submaximal tachycardic response, physiologic responses at maximal workloads were not different after cannabis consumption [44]. Examination of submaximal through maximal work clearly shows a diminishing difference between placebo and cannabis groups as exercise intensity is increased. At workloads greater than $80 \%$ of maximal effort no differences existed, calling into question the implications of previous submaximal work for modelling effects of performance, especially as $V \mathrm{O}_{2 \max }$ is not affected [44]. The most lauded finding from the work of Renaud and Cormier [44] was the fact that there was a significant difference in exercise duration, with cannabis exposure decreasing time to exhaustion. While the data do indeed support this finding, examination of the exercise testing protocol demonstrates that this difference $(16.1 \pm 4$ vs $15.1 \pm 3 \mathrm{~min}$ ) represents an average difference of a single one-minute stage, and $100 \mathrm{kpm} / \mathrm{min}$, or about $16 \mathrm{~W}$. It is unclear if this was truly a scaled linear variable (time), or if it was an ordinal variable - such that participants were encouraged to finish each stage with only finished stages being counted. In either case, the implications of such a small magnitude change on this type of staged test are questionable. As this is truly the only investigation of exhaustive performance in healthy participants, the methodological ambiguity and debatable practical validity of the findings indicate that further work is warranted.

\subsection{Knowledge Gaps and Recommendations}

There is a paucity of valid exercise studies designed to specifically investigate the effects of cannabis and THC on human exercise capacity and performance. It is noted that physiological capacity and performance are interrelated, but not equivalent. Factors such as an athlete's perception (e.g., 
time, pain, appropriate pacing strategies) and motivation ultimately affect performance and could also be altered by cannabis or THC, but have not been investigated. Healthy subjects who have varied levels of fitness and habituation to cannabis need to be studied, with further consideration of the methods of cannabis intake and the pharmacokinetics that dictate the time of peak effects. Dose-response curves should be developed, with varied exercise modes (e.g., cycling, running, strength assessments), intensities (i.e., submaximal, maximal, sprint-power based), durations (e.g., up to and including ultra-endurance events) and models of performance (time to exhaustion, time trial, power output). Improved technologies, including electronically braked ergometers and breath-by-breath indirect calorimetry, now allow research to move beyond the incremental-stage graded exercise test. These contemporary technologies and best practices should be employed to increase the sensitivity and validity for tests of physical capacity and performance.

\section{Cannabis and Systems-Level Cardiorespiratory Physiology}

While the bona fide effects of cannabis on athletic performance are limited by an incomplete evidence-base with low ecological validity for athletes, the physiological actions of cannabis and THC offer important insight into perturbations of cardiorespiratory homeostasis through which cannabis may interact with performance. Studies from these areas have generally been considered separately (for reviews of cannabis and performance see $[9,21,27,30-36]$; for reviews of cardiovascular effects of cannabis see $[22,25]$ ) with no comprehensive integration. As exercise clearly requires a coordinated and integrated response from multiple physiological systems, this is a notable shortcoming.

Studies administering cannabis and isolated THC to healthy individuals have revealed a wide range of cardiovascular effects, including: changes in heart rate [41-45, 53-85], cardiac function [55, 59, 64, 75, 76, 79, 83], blood pressure $[41,42,53,57,59-61,63-65,75-78,83]$, orthostatic hypotension $[53,60,80]$, ventilatory sensitivity to carbon dioxide [61], and limb blood flow [53, 78, 85].

Transient sinus tachycardia is a commonly reported dosedependent effect of cannabis and THC consumption [55, $68,70,72,82,83]$. As noted for the performance literature, this effect persists during submaximal exercise, resulting in a greater rate-pressure product at a given exercise intensity, indicative of increased myocardial oxygen demand [86]. When consumed via smoking, this elevated myocardial oxygen demand associated with cannabis consumption could be exacerbated by reduced oxygen supply consequent to the inhaled carbon monoxide present in cannabis smoke [87].
The disruption of the myocardial oxygen supply/demand relationship likely explains why myocardial ischemia is precipitated by cannabis smoking in coronary heart disease patients [42, 45]. It is worth noting this phenomenon may not be unique to cannabis smoking, as placebo and traditional cigarette smoking in these same studies induced an attenuated, but still significant, reduction in time to angina compared to cannabis, likely due to the fact that all smoking involves the inhalation of carbon monoxide and hydrocarbons but does not produce the cannabis specific tachycardic effect.

The acute effects of cannabis and THC consumption on blood pressure are more variable, with potential implications for perfusion during exercise. Investigators have reported increases in systolic and diastolic pressure [41, $42,53,59,61,64,65,76-78,83]$, reductions in blood pressure $[60,63]$, or no changes in blood pressure [43, $58,59,62,63,73-75,81,88-90]$ following cannabis or THC consumption. Unlike HR, it appears that pressure responses during exercise are not affected following a single instance of cannabis consumption [43]. However, if THC is persistently administered in high doses (up to $210 \mathrm{mg} /$ day for multiple weeks) blood pressure responses to exercise are altered; with an attenuation of the rise in systolic blood pressure, and an exaggeration of the reduction in diastolic blood pressure [77]. Thus, the timing and quantity of THC dose may also influence the pressor response to exercise. The reported increase in limb blood flow following cannabis consumption [53, 78, 85] could also partially explain the varied effects on pressure, but limb blood flow following cannabis and THC consumption has only been examined at rest. During exercise performance, cannabis induced increases in flow could be relevant given limited evidence that suggests that muscle blood flow may, to some degree, limit maximal exercise capacity [91]. Further studies are needed to reach conclusions about how these hemodynamic effects of cannabis and THC interact with performance outcomes.

Echocardiographic studies have generated equivocal findings with respect to cardiac function, reporting both reduced systolic function [59] and increased left ventricular tissue velocity $[64,76]$ following cannabis smoking. Whether the myocardial effects of cannabis and THC impact exercise performance remains unclear, owing largely to uncertainty over whether the effects observed at rest persist during exerciseand if so, the extent of functional consequences. Employing modern tests of cardiac function and imaging techniques, such as stress echocardiography [92] or magnetic resonance imaging [93], is required to fill this knowledge gap, as imaging and analysis capabilities have evolved substantially since the publication of the aforementioned seminal works. The importance of cardiac mechanics (such as left ventricular 
strain, torsion and twist) for understanding cardiac function is increasingly recognized $[94,95]$; yet to date only two studies have examined these variables in chronic cannabis users $[96,97]$, and no studies have examined the acute effects of cannabis or THC.

A large body of evidence from in-vitro and animal models indicates that the mechanisms through which cannabis and THC elicit cardiovascular effects are likely vast and many could be relevant to exercise performance (for review, see [25]). In humans the cardiovascular effects of THC and cannabis appear to be largely mediated through autonomic nervous mechanisms and the endocannabinoid system. Treatment with beta-adrenergic blockade prior to THC or cannabis administration markedly blunts tachycardic [65, 75, 84, 85] and pressor $[65,75]$ responses, increases in limb blood flow [78, 85], and alterations to systolic time intervals [75]. Thus, it appears that the cardiovascular effects of THC and cannabis are mediated at least partially through the sympathetic nervous system. Beta-adrenergic blockade in combination with anti-cholinergic agents augments the effects of THC and cannabis on HR and blood pressure [75, 77, 78, 85]. The endogenous cannabinoid system also appears able to facilitate certain cardiovascular effects of THC, suggesting a degree of redundancy. Following the discovery of the endocannabinoid system and identification of CB1 in cardiovascular tissues [98, 99], investigations of human participants revealed that inhibition of $\mathrm{CB} 1$ also ablates the tachycardic effects of cannabis [69, 70, 72-74, 89, 100]. Despite these putative mechanisms through which cannabis and THC exert cardiovascular effects, cannabis contains hundreds of chemical compounds, including over 100 phytocannabinoids [10]. Thus, it should be accepted that the physiological effects of cannabis cannot be solely attributed to THC until further investigations examine the many constituents of the plant.

Given the inseparable links of the cardiovascular and respiratory systems to support aerobic exercise performance, the effects of cannabis and THC consumption on respiratory function must be considered. Epidemiological analyses of the respiratory effects of chronic cannabis use have failed to show a clear linear relationship between cannabis smoking and reduced pulmonary function [101], and generally only demonstrate reduced function with very heavy cannabis use [102]. Thus, it may be that exercise capacity is, similarly, only impacted negatively with heavy cannabis use. Cross-sectional data comparing $V \mathrm{O}_{2 \max }$, work capacity, pulmonary function, and strength and endurance outcomes have consistently demonstrated no differences between young cannabis users and non-users [37-40]; however, no comparison has been made between non-users and longtime heavy users.

The acute and transient effects of cannabis and THC on respiratory function during exercise have received little attention. Of the two studies performed in healthy individuals, one revealed no differences in respiratory function [41], and the other demonstrated an increased capacity to expire forcefully $\left(\mathrm{FEV}_{1}\right)$ after exercise [44]. Alterations in flow are most likely related to the reported bronchodilator effects of THC [103]. Theoretically, the ability of THC to induce bronchodilation in healthy and asthmatic participants [104] provides a potential mechanism through which cannabis could influence performance, as bronchodilating substances have previously been used by athletes for purported ergogenic effects [105]. However, the ergogenic potential of this bronchodilator effect remains to be confirmed, and it is notable that COPD patients experienced no improvement in exercise capacity or respiratory function following inhalation of vaporized cannabis [46]. It must also be considered that a number of bronchodilating substances are currently permitted for use in sport by WADA [106], and the evidence supporting the ergogenic effects of bronchodilating substances is tenuous [107]. Another intriguing observation is that THC appears to alter ventilatory sensitivity to carbon dioxide [61]. At present, it is not clear whether this effect occurs, or is consequential, during exercise.

There currently exists a substantial body of evidence demonstrating that consumption of cannabis leads to numerous systemic cardiorespiratory effects at rest, largely due to the actions of THC. Despite increasing use of recreational and medicinal cannabis, it remains unclear which effects persist during dynamic exercise, and how they might impact performance. Understanding these effects is not only necessary to determine how cannabis impacts performance across athletic disciplines, but also to inform decisions regarding the safety and regulation of cannabis use in both athletic and non-athletic populations.

\subsection{Knowledge Gaps and Recommendations}

The effects of cannabis and THC on rudimentary cardiorespiratory physiology in resting humans are well characterized; however, both cannabis potency and investigative research capabilities have increased dramatically since many of these studies were initially performed, without concomitant study. The independent effects of inhaling combusted plant material versus the effects of cannabis and THC are incompletely understood, both at rest and in an exercise context. For future work to successfully characterize the effects of cannabis and THC on performance, underlying physiological effects must be rigorously investigated before, during, and after exercise. 


\section{CBD and the Elite Athlete}

While whole cannabis is commonly used across the globe for both recreational and medicinal purposes [9] in many countries it remains an illicit drug [108], and from an athletic perspective it is currently prohibited (in competition) by WADA. However, one of the major phytocannabinoids within cannabis, CBD, was specifically removed from the WADA prohibited list in 2018 and as a consequence its interest in sport has grown exponentially. Interest in CBD is also largely driven by the fact that the L-isomer of CBD originating from cannabis plants does not have psychotropic properties, although some synthetic analogs might [109]. The use of CBD in sport has recently been reviewed extensively [110]. The individual phytocannabinoid derivatives from the cannabis plant face discrepant restrictions by some sporting governing bodies and WADA [106]. Of all the phytocannabinoid derivatives, the only constituent absolutely legal from a WADA perspective is CBD. All other phytocannabinoid derivatives are prohibited per se except THC which is considered a threshold substance, meaning that only concentrations $>150 \mathrm{ng} / \mathrm{ml}$ in urine result in an anti-doping rule violation (ADRV) [111]. It is also important to stress that the legislative regulation of CBD itself is somewhat complex and it is, therefore, vital that athletes are aware of the specific country, and in the case of the US, state specific legislation before considering the potential for CBD use in sport. Despite this lack of clarity surrounding the precise legality of CBD commerce and consumption, supplementation in athletic populations has grown due to its purported effects on athletic performance and recovery $[9,20]$.

\subsection{Sleep and Anxiety}

Appropriate sleep is widely accepted as an integral component of the recovery process in athletes (for review see [112]). Professional athletes have previously reported suboptimal sleep quantity [113] and quality [114]. Indeed, disturbances in sleep can be a consequence of several mechanisms including pre-game supplementation [115], the time of competition [116], implications of long-haul travel [117], and anxiety associated with competition [118-121]. It is, therefore, understandable that athletes supplement products such as CBD, with the aim to improve sleep efficiency and provide anxiolytic properties [122], despite associated evidence being limited to clinical research as opposed to within elite athlete cohorts.

Any potential positive effects of CBD on sleep are primarily limited to diseased populations, such as sufferers of Parkinson's disease [123] and post-traumatic stress disorders [122], with randomized controlled trials in human participants somewhat limited. However, Carlini \& Cunha reported that CBD supplementation $(160 \mathrm{mg})$ significantly increased sleep duration in individuals reporting difficulties in both sleep onset and quality [124]; however, conclusions were limited to perceived/subjective measures as opposed to objective polysomnographic data. More recent research from Linares and colleagues showed no significant effects of CBD (300 mg) on either subjective sleep quality or objective polysomnography measures, though it is important to note that although the latter utilized a higher dose of CBD, participants were healthy and not experiencing any reported sleep disturbance [125]. As such, although CBD shows promise in sleep quantity and quality, well-designed randomized controlled studies in athletic populations are required to determine the exact, if any, situation in which CBD may provide this sleep (and thus recovery) enhancing effect.

\subsection{Pain, Inflammation, and Muscle Function}

Exercise induced muscle damage (EIMD) is a well-established phenomenon following athletic activity (for review see [126]). Throughout congested competition schedules and particularly damaging exercise bouts [127], pain and recovery management is often modulated via non-steroidal antiinflammatory drugs (NSAIDs) and, in some cases, opiates [128]. However, in addition to the adaptation blunting effect of NSAIDs [126], chronic consumption has the potential to induce several adverse health effects [129]. It is, therefore, unsurprising that in a recent study of elite rugby players, $26 \%$ of players had previously experimented, or were currently using CBD supplements, which have been shown to have mild-moderate adverse effect profiles in humans [130, 131]. That said, as a result of CBD's metabolism by the CYP3A4 and CYP219 enzymes it can potentially increase drug-drug interactions with other compounds metabolized by the same enzymes, subsequently increasing potential adverse effects profiles [132]. In this study, $\sim 80 \%$ of rugby players cited pain management as their primary motive for experimenting with CBD [20]. This high prevalence of use was in spite of the current lack of an evidence-base for the efficacy of supplementation, and risks of potential ADRVs [20, 133]. Interestingly, despite the high number of rugby players taking CBD for pain modulation, only $14 \%$ of rugby players reported any beneficial effect [20]. These findings may be as a result of the disparity in the reported doses consumed by athletes [20], especially as higher doses may be required to offer anti-inflammatory effect in humans. Low vs. high doses of CBD (10 vs. $500 \mathrm{mg} /$ day) have shown differing pain alleviating results (non-significant vs. significant) in patients experiencing high levels of gastrointestinal inflammation [134, 135], with higher dosages, although significantly relieving pain, also resulting in issues within the gastrointestinal tract or central nervous system. It is worth 
noting that the population of this study already had gastrointestinal issues, which may, in part, explain these increased adverse effects [135].

Despite the widespread inclusion of strength training amongst high-level athletes, studies investigating the effects of CBD supplementation on resistance exercise are extremely limited. To date, only two preliminary studies are available with varying research designs, and equivocal findings. For example, $150 \mathrm{mg}$ day of oral CBD $(2 \times 75 \mathrm{mg}$ doses given immediately post, 24 and $48 \mathrm{~h}$ following a muscle-damaging protocol) had no beneficial effects on either muscle function or perceived soreness in untrained males $(n=13)$ [136]. The only other available data on CBD and muscle soreness in an athletic context are limited to a single abstract from a conference communication [137]. This study assessed muscle damage (via creatine kinase [CK]) following a single bout of resistance exercise and suggested that CBD supplementation $(60 \mathrm{mg} / \mathrm{day})$ attenuated the acute increases in CK. However, alongside the proposed reduction in muscle damage, there were also reductions in strength within $24 \mathrm{~h}$ of supplementation. It is important to consider that neither of these studies assessed blood or urine cannabinoid concentrations and the equivocal data could be related to the efficacy of the supplementation protocols with major differences in the actual dose of $\mathrm{CBD}$, number of days supplemented, and route of administration. Collectively, the evidence to date on the effects of CBD on muscle function following damaging exercise could be, at best, described as 'in its infancy' and, therefore, it is not possible to reach any form of conclusion as to the efficacy of CBD for muscle recovery. Research is now required, including pharmacokinetic data, measures of blood cannabinoids, and dose-response data to fully explore if CBD is able to attenuate muscle damage and/or enhance recovery following exercise.

\subsection{Neuroprotection and Traumatic Brain Injury}

Concussion is a type of mild traumatic brain injury (mTBI) [138] which may occur following a rapid deceleration or rotational force applied to the brain [139]. These biomechanical mechanisms of injury are a particular concern in collision and combat sports such as rugby union [140], rugby league [141] American football [142, 143], as well as boxing and mixed-martial arts [144]. Several acute side-effects may be experienced during concussion including headaches, cognitive impairments, sleep disruption, and behavioral changes [145]. Moreover, long-term effects of concussion can include behavioral changes leading to aggressive episodes, anxiety, and depression [146]. Despite the exact mechanisms by which this may be achieved being unconfirmed, CBD has been proposed to offer a protective benefit in athletes who are "at risk" of mTBI in sport [147]. Suggested mechanisms include the anti-inflammatory nature of CBD [148, 149], anandamide uptake and enzymatic hydrolysis [150], and/ or a decrease in adenosine reuptake [151]. To date, a single murine study has investigated the effects of CBD on mTBI [147]. In this study the authors concluded that chronic CBD administration (equating to $\sim 51 \mathrm{mg} / \mathrm{day}$ when converted to a human equivalent dose [152]) reduces dysfunctions relating to the anxious, aggressive and depressive behaviors often exhibited following mTBI. Given the severe consequences of mTBI to health, coupled with the proposed neuroprotective potential of CBD, it is imperative that additional investigation in this area be completed in humans to understand the mechanisms by which CBD may offer a neuroprotective benefit to athletes who are at risk of mTBI.

\subsection{Knowledge Gaps and Recommendations}

As a consequence of the complicated legislative status of CBD, research in-vivo is less common than for other ergogenic supplements regularly consumed by athletes. Whilst many CBD products available for purchase without prescription claim to have negligible, or even $0 \%$ THC, these claims are sometimes unfounded with a recent study suggesting that only 3 of a selected 25 CBD products were within $\pm 20 \%$ of claims made on their respective containers [153]. Moreover, many CBD products that are THC free still contain other cannabinoids, which are prohibited by WADA, and detection may result in ADRVs. Indeed, as THC can be stored in fat tissue [154], blood and urine metabolites may peak following specific periods of lipolysis inducing exercise [154] or fasting [155]. When considering CBD products athletes should also ensure that the L-isomer is the molecule contained, and be aware of the potential presence of other CBD analogs, which could possess psychotropic properties that may not be desired [109]. It is also important to consider that where CBD has been suggested as the root cause of significant findings, there may in fact be an 'entourage effect' as other cannabinoids may be present [156]. From a safety perspective, despite being reported to have a reasonably low adverse effects profile, there appear to be significant drug metabolism interactions, as CBD is metabolized by CYP450 isoforms 2C19 and 3A4 [157, 158]. Approximately $60 \%$ of clinically prescribed medications are metabolized by CYP3A4 and as a consequence there are suggestions that CBD can increase the adverse effects profile of standard medications such as clobazam used to treat epilepsy [130]. Subsequently, future research should investigate the efficacy of CBD in its therapeutic role in pain and recovery management, sports-related anxiolytic and sleep promoting effects, and examine drug interactions and side effect profiles of 
CBD supplementation. It is essential that studies begin to further investigate the mechanistic properties of CBD (and any 'entourage effect'), as well as explore translatable mechanistic findings in-vivo.

\section{Conclusions}

Cannabis and individual cannabinoids have a clear capacity to affect certain facets of human physiology; however, the applicability of such physiological perturbations to affect improvements in the health, performance, or recovery of athletes remains incomplete owing to large knowledge gaps and low-quality existing evidence stemming from substantial barriers to conducting high quality cannabis research $[2,3]$. Herein, we have provided an overview of the existing evidence and areas for future research. Unlike CBD, cannabis and THC are prohibited by WADA in-competition, and while the cardiorespiratory effects at rest of cannabis and THC are well described, both the short- and long-term effects on the human capacity for exercise require well-controlled, athlete-specific research, with applied performance outcomes. Additional work will be required to understand the dose-response of these effects, accounting for methods of consumption, timing around exercise and cannabinoid concentrations. Such data are essential for weighing the evidence for or against prohibition both in and out of competition. The use of CBD by athletes is likely more relevant to recovery during training and while in competition. CBD may have some promise for improving athlete pain and recovery through a number of potential mechanisms, although evidence to support this to date is extremely limited. Moreover, the use of CBD requires prudent attention to local regulations and contamination with prohibited cannabinoids could trigger doping violations.

Acknowledgements This supplement is supported by the Gatorade Sports Science Institute (GSSI). The supplement was guest edited by Lawrence L. Spriet, who convened a virtual meeting of the GSSI Expert Panel in October 2020 and received honoraria from the GSSI, a division of PepsiCo, Inc., for his participation in the meeting. Dr Spriet received no honoraria for guest editing the supplement. Dr Spriet suggested peer reviewers for each paper, which were sent to the Sports Medicine Editor-in-Chief for approval, prior to any reviewers being approached. Dr Spriet provided comments on each paper and made an editorial decision based on comments from the peer reviewers and the Editor-in-Chief. Where decisions were uncertain, Dr Spriet consulted with the Editor-in-Chief. The views expressed in this manuscript are those of the authors and do not necessarily reflect the position or policy of PepsiCo, Inc.

\section{Declarations}

Funding This article is based on a presentation by Jamie Burr and Graeme Close to the GSSI Expert Panel Virtual Meeting in October
2020. An honorarium for participation in the meeting and preparation of this article was provided by the GSSI. No other sources of funding were used to assist in the preparation of this article.

Conflicts of interest Graeme Close has received funding from Naturecan Ltd. Jamie Burr, Christian Cheung, Andreas Kasper and Scott Gillham declare that they have no conflicts of interest relevant to the content of this review.

Author contributions All authors contributed to drafting the manuscript, and all authors edited and approved the final manuscript.

Open access This article is licensed under a Creative Commons Attribution 4.0 International License, which permits use, sharing, adaptation, distribution and reproduction in any medium or format, as long as you give appropriate credit to the original author(s) and the source, provide a link to the Creative Commons licence, and indicate if changes were made. The images or other third party material in this article are included in the article's Creative Commons licence, unless indicated otherwise in a credit line to the material. If material is not included in the article's Creative Commons licence and your intended use is not permitted by statutory regulation or exceeds the permitted use, you will need to obtain permission directly from the copyright holder. To view a copy of this licence, visit http://creativecommons.org/licenses/by/4.0/.

\section{References}

1. Frankhauser M. History of Cannabis in Western medicine. In: Grotterman F, Russo E, editors. Cannabis cannabinoids pharmacol toxicol ther potential. Binghampton: Routledge; 2013. p. 37.

2. Haney M. Perspectives on cannabis research-barriers and recommendations. JAMA Psychiat. 2020;77:994-5.

3. Martin JH, Hill C, Walsh A, Efron D, Taylor K, Kennedy M, et al. Clinical trials with cannabis medicines-guidance for ethics committees, governance officers and researchers to streamline ethics applications and ensuring patient safety: considerations from the Australian experience. Trials BioMed Central. 2020;21:1-7.

4. Lorente FO, Peretti-Watel P, Grelot L. Cannabis use to enhance sportive and non-sportive performances among French sport students. Addict Behav. 2005;30:1382-91.

5. Peretti-Watel $P$, Guagliardo V, Verger P, Pruvost J, Mignon $P$, Obadia Y. Sporting activity and drug use: alcohol, cigarette and cannabis use among elite student athletes. Addiction. 2003;98:1249-56.

6. Brisola-Santos MB, de Gallinaro JG, Gil F, Sampaio-Junior B, Marin MCD, de Andrade AG, et al. Prevalence and correlates of cannabis use among athletes-A systematic review. Am J Addict. 2016;25:518-28.

7. Campian MD, Flis AE, Teramoto M, Cushman DM. SelfReported use and attitudes toward performance-enhancing drugs in ultramarathon running. Wilderness Environ Med. 2018;29:330-7.

8. World Drug Report-Booklet 2: drug use and health consequences. United Nations Publ. 2020.

9. Docter S, Khan M, Gohal C, Ravi B, Bhandari M, Gandhi R, et al. Cannabis use and sport: a systematic review. Sports Health. 2020;12:189-99.

10. Amin MR, Ali DW. Pharmacology of medical cannabis. Adv Exp Med Biol. 2019;1162:151-65. 
11. Ashton $\mathrm{CH}$. Pharmacology and effects of cannabis: A brief review. Br J Psychiatry. 2001;178:101-6.

12. Pertwee R. Pharmacology of cannabinoid CB1 and CB2 receptors. Pharmacol Ther. 1997;74:129-80.

13. Anand P, Whiteside G, Fowler CJ, Hohmann AG. Targeting CB2 receptors and the endocannabinoid system for the treatment of pain. Brain Res Rev. 2009;60:255-66.

14. Niesink RJM, van Laar MW. Does cannabidiol protect against adverse psychological effects of THC? Front Psychiatry. 2013;4:130.

15. Laprairie RB, Bagher AM, Kelly MEM, Denovan-Wright EM. Cannabidiol is a negative allosteric modulator of the cannabinoid CB1 receptor. Br J Pharmacol. 2015;172:4790-805.

16. Sparling PB, Giuffrida A, Piomelli D, Rosskopf L, Dietrich A. Exercise activates the endocannabinoid system. NeuroReport. 2003;14:256-77.

17. Huestis MA, Sampson AH, Holicky BJ, Henningfield JE, Cone EJ. Characterization of the absorption phase of marijuana smoking. Clin Pharmacol Ther. 1992;52:31-41.

18. Schlienz NJ, Spindle TR, Cone EJ, Herrmann ES, Bigelow GE, Mitchell JM, et al. Pharmacodynamic dose effects of oral cannabis ingestion in healthy adults who infrequently use cannabis. Drug Alcohol Depend. 2020;211:107969.

19. Grotenhermen F. Pharmacokinetics and pharmacodynamics of cannabinoids. Clin Pharmacokinet. 2003;42:327-60.

20. Kasper AM, Sparks SA, Hooks M, Skeer M, Webb B, Nia H, et al. High prevalence of cannabidiol use within male professional rugby union and league players : a quest for pain relief and enhanced recovery. Int J Sport Nutr Exerc Metab. 2020;30:315-22.

21. Huestis MA, Mazzoni I, Rabin O. Cannabis in sport: anti-doping perspective. Sport Med. 2011;41:949-66.

22. Jones RT. Cardiovascular system effects of marijuana. J Clin Pharmacol. 2002;42:58S-63S.

23. Ribeiro LIG, Ind PW. Effect of cannabis smoking on lung function and respiratory symptoms: a structured literature review. Prim Care Respir Med. 2016;26:1-8.

24. Crean RD, Crane NA, Mason BJ. An evidence based review of acute and long-term effects of cannabis use on executive cognitive functions. J Addict Med. 2011;5:1.

25. Pacher P, Steffens S, Haskó G, Schindler TH, Kunos G. Cardiovascular effects of marijuana and synthetic cannabinoids: the good, the bad, and the ugly. Nat Rev Cardiol. 2018;15:151-66.

26. Hall W, Degenhardt L. Adverse health effects of non-medical cannabis use. Lancet. 2009;374:1383-91.

27. Saugy M, Avois L, Saudan C, Robinson N, Giroud C, Mangin P, et al. Cannabis and sport. Br J Sports Med. 2006;40:i13-5.

28. Goyal H, Awad HH, Ghali JK. Role of cannabis in cardiovascular disorders. J Thorac Dis. 2017;9:2079-92.

29. Kvålseth TO. Effects of marijuana on human reaction time and motor control. Percept Mot Skills. 1977;45:935-9.

30. Kennedy MC. Cannabis: exercise performance and sport. A systematic review. J Sci Med Sport. 2017;20:825-9.

31. Ware M, Jensen D, Barrette A, Vernec A, Derman W. Cannabis and the health and performance of the elite athlete. Clin J Sport Med. 2018;1992:480-4.

32. Charron J, Carey V, Marcotte L'Heureux V, Roy P, Comtois AS, Ferland PM. Acute effects of cannabis consumption on exercise performance: a systematic and umbrella review. J Sports Med Phys Fitness. 2021;61:551-61.

33. Pesta DH, Angadi SS, Burtscher M, Roberts CK. The effects of caffeine, nicotine, ethanol, and tetrahydrocannabinol on exercise performance. Nutr Metab. 2013;10:1-15.

34. Campos DR, Yonamine M, De Moraes Moreau RL. Marijuana as doping in sports. Sport Med. 2003;33:395-9.
35. Huestis MA. Cannabis (marijuana) - effects on human behavior and performance. Forensic Sci Rev. 2002;14:16-60.

36. Gillman AS, Hutchison KE, Bryan AD. Cannabis and exercise science: a commentary on existing studies and suggestions for future directions. Sport Med. 2015;45:1357-63.

37. Lisano JK, Kisiolek JN, Smoak P, Phillips KT, Stewart LK. Chronic cannabis use and circulating biomarkers of neural health, stress, and inflammation in physically active individuals. Appl Physiol Nutr Metab. 2020;45:258-63.

38. Maksud MG, Baron A. Physiological responses to exercise in chronic cigarette and marijuana users. Eur J Appl Physiol Occup Physiol. 1980;43:127-34.

39. Lisano JK, Smith JD, Mathias AB, Christensen M, Smoak P, Phillips KT, et al. Performance and health-related characteristics of physically active males using marijuana. J Strength Cond Res. 2019;33:1658-68.

40. Wade NE, Gilbart E, Swartz AM, Lisdahl KM. Assessing aerobic fitness level in relation to affective and behavioral functioning in emerging adult cannabis users. Int J Ment Health Addict. 2019;2019:1-14.

41. Steadward RD, Singh M. The effects of smoking marihuana on physical performance. Med Sci Sports Exerc. 1975;7:309-11.

42. Aronow WS, Cassidy J. Effect of marihuana and placebomarihuana smoking on angina pectoris. N Engl J Med. 1974;291:65-7.

43. Avakian EV, Horvath SM, Michael ED, Jacobs S. Effect of marihuana on cardiorespiratory responses to submaximal exercise. Clin Pharmacol Ther. 1979;26:777-81.

44. Renaud AM, Cormier Y. Acute effects of marihuana smoking on maximal exercise performance. Med Sci Sport Exerc. 1986;18:685-9.

45. Aronow WS, Cassidy J. Effect of smoking marihuana and of a high-nicotine cigarette on angina pectoris. Clin Pharmacol Ther. 1975;17:549-54.

46. Abdallah SJ, Smith BM, Ware MA, Moore M, Li PZ, Bourbeau $\mathrm{J}$, et al. Effect of vaporized cannabis on exertional breathlessness and exercise endurance in advanced chronic obstructive pulmonary disease: a randomized controlled trial. Ann Am Thorac Soc. 2018;15:1146-58.

47. Preuss UW, Watzke AB, Zimmermann J, Wong JWM, Schmidt CO. Cannabis withdrawal severity and short-term course among cannabis-dependent adolescent and young adult inpatients. Drug Alcohol Depend Elsevier. 2010;106:133-41.

48. Sanders D, van Erp T. The physical demands and power profile of professional men's cycling races: an updated review. Int J Sports Physiol Perform. 2020;1:1-10.

49. Borg GA, Dahlstrom H. The reliability and validity of a physical work test. Acta Physiol Scand. 1962;55:353-61.

50. Hawley JA, Noakes TD. Peak power output predicts maximal oxygen uptake and. Eur J Appl Physiol Occup Physiol. 1992;65:79-83.

51. Bell DG, Jacobs I, McLellan TM, Zamecnik J. Reducing the dose of combined caffeine and ephedrine preserves the ergogenic effect. Aviat Sp Environ Med. 2000;71:415-9.

52. Bell DG, Mclellan TM, Sabiston CM. Effect of ingesting caffeine and ephedrine on 10-km run performance. Med Sci Sport Exerc. 2001;34:344-9.

53. Weiss JL, Watanabe AM, Lemberger L, Tamarkin NR, Cardon PV. Cardiovascular effects of delta-9-tetrahydrocannabinol in man. Clin Pharmacol Ther. 1972;13:671-84.

54. Perez-Reyes M, Timmons MC, Lipton MA. Intravenous injection in man of delta-9-tetrahydrocannabinol and 11-hydroxy-delta9-tetrahydrocannabinol. Science. 1972;177:633-5.

55. Kochar MS, Hosko MJ. Electrocardiographic effects of marihuana. JAMA. 1973;225:25-7. 
56. Roth WT, Tinklenberg JR, Kopell BS, Hollister LE. Continuous electrocardiographic monitoring during marihuana intoxication. Clin Pharmacol Ther. 1973;14:533-40.

57. Clark CS, Greene C, Karr G, MacCannell K, Milstein S. Cardiovascular effects of marihuana in man. Can J Physiol Pharmacol. 1974;52:706-19.

58. Karniol IG, Shirakawa I, Takahashi RN, Knobel E, Musty RE. Effects of delta-9-tetrahydrocannabinol and cannabinol in man. Pharmacology. 1975;13:502-12.

59. Prakash R, Aronow WS, Warren M, Laverty W, Gottschalk LA. Effects of marihuana and placebo marihuana smoking on hemodynamics in coronary disease. Clin Pharmacol Ther. 1975;18:90-5.

60. Benowitz NL, Jones RT. Cardiovascular effects of prolonged delta-9-tetrahydrocannabinol ingestion. Clin Pharmacol Ther. 1975;18:287-97.

61. Malit LA, Johnstone RE, Bourke DI, Kulp RA, Klein V, Smith TC. Intravenous delta-9-tetrahydrocannabinol: effects on ventilatory control and cardiovascular dynamics. Anesthesiology. 1975;42:666-73.

62. Bernstein JG, Kuehnle JC, Mendelson JH. Medical implications of marijuana use. Am J Drug Alcohol Abuse. 1976;3:347-61.

63. Gregg JM, Campbell RL, Levin KJ, Ghia J, Elliott RA. Cardiovascular effects of cannabinol during oral surgery. Anesth Analg. 1976;55:203-13.

64. Tashkin DP, Levisman JA, Abbasi AS, Shapiro BJ, Ellis NM. Short term effects of smoked marihuana on left ventricular function in man. Chest. 1977;72:20-6.

65. Sulkowski A, Vachon L, Rich ES. Propranolol effects on acute marihuana intoxication in man. Psychopharmacology. 1977;52:47-53

66. Mendelson JH, Mello NK. Reinforcing properties of oral $\Delta$ 9-tetrahydrocannabinol, smoked marijuana, and nabilone: influence of previous marijuana use. Psychopharmacology. 1984;83:351-6

67. Lex BW, Mendelson JH, Bavli S, Harvey K, Mello NK. Effects of acute marijuana smoking on pulse rate and mood states in women. Psychopharmacology. 1984;84:178-87.

68. Kelly TH, Foltin RW, Fischman MW. Effects of smoked marijuana on heart rate, drug ratings and task performance by humans. Behav Pharmacol. 1993;4:167-78.

69. Huestis MA, Boyd SJ, Heishman SJ, Preston KL, Bonnet D, Le Fur G, et al. Single and multiple doses of rimonabant antagonize acute effects of smoked cannabis in male cannabis users. Psychopharmacol Berl. 2007;194:505-15.

70. D'Souza DC, Ranganathan M, Braley G, Gueorguieva R, Zimolo Z, Cooper T, et al. Blunted psychotomimetic and amnestic effects of $\Delta$-9-tetrahydrocannabinol in frequent users of cannabis. Neuropsychopharmacology. 2008;33:2505-16.

71. Cooper ZD, Haney M. Comparison of subjective, pharmacokinetic, and physiologic effects of marijuana smoked as joints and blunts. Drug Alcohol Depend. 2009;103:107-13.

72. Zuurman L, Roy C, Schoemaker RC, Amatsaleh A, Guimaeres L, Pinquier JL, et al. Inhibition of THC-induced effects on the central nervous system and heart rate by a novel CB1 receptor antagonist AVE1625. J Psychopharmacol. 2010;24:363-71.

73. Klumpers LE, Roy C, Ferron G, Turpault S, Poitiers F, Pinquier $\mathrm{JL}$, et al. Surinabant, a selective cannabinoid receptor type 1 antagonist, inhibits $\Delta 9$-tetrahydrocannabinol-induced central nervous system and heart rate effects in humans. Br J Clin Pharmacol. 2013;76:65-77.

74. Englund A, Atakan Z, Kralj A, Tunstall N, Murray R, Morrison $P$. The effect of five day dosing with THCV on THC-induced cognitive, psychological and physiological effects in healthy male human volunteers: a placebo-controlled, double-blind, crossover pilot trial. J Psychopharmacol. 2016;30:140-51.
75. Kanakis C, Pouget JM, Rosen KM. Lack of cardiovascular effects of delta-9-tetrahydrocannabinol in chemically denervated men. Ann Intern Med. 1979;91:571-4.

76. Gash A, Karliner JS, Janowsky D, Lake CR. Effects of smoking marihuana on left ventricular performance and plasma norepinephrine. Ann Intern Med. 1978;89:448-52.

77. Benowitz NL, Jones RT. Prolonged delta-9-tetrahydrocannabinol ingestion effects of sympathomimetic amines and autonomic blockades. Clin Pharmacol Ther. 1977;21:336-42.

78. Benowitz NL, Rosenberg J, Rogers W, Bachman J, Jones RT. Cardiovascular effects of intravenous delta-9-tetrahydrocannabinol: autonomic nervous mechanisms. Clin Pharmacol Ther. 1979;25:440-6.

79. Kanakis C, Pouget JM, Rosen KM. The effects of delta-9-tetrahydrocannabinol (cannabis) on cardiac performance with and without beta blockade. Circulation. 1976;53:703-7.

80. Renault PF, Schuster CR, Freedman DX, Sikic B, de Mello DN, Halaris A. Repeat administration of marihuana smoke to humans. Arch Gen Psychiatry. 1974;31:95-102.

81. Isbell H, Gorodetzsky CW, Jasinski D, Claussen U, Spulak FV, Korte F. Effects of (-) $\Delta$ 9-trans-tetrahydrocannabinol in man. Psychopharmacologia. 1967;11:184-8.

82. Renault PF, Schuster CR, Heinrich R, Freeman DX. Marihuana: standardized smoke administration and dose effect curves on heart Rate in humans. Science. 1971;174:589-91.

83. Johnson S, Domino FE. Some cardiovascular effects of marihuana smoking in normal volunteers. Clin Pharmacol Ther. 1971;12:762-8.

84. Martz R, Brown DJ, Forney RB, Sright TP, Kiplinger GF, Rodda BE. Propranolol antagonism of marihuana induced tachycardia. Life Sci. 1972;11:999-1005.

85. Beaconsfield P, Ginsburg J, Rainsbury R. Marihuana smoking cardiovascular effects in man and possible mechanisms. N Engl J Med. 1972;287:209-12.

86. Gobel FL, Norstrom LA, Nelson RR, Jorgensen CR, Wang Y. The rate-pressure product as an index of myocardial oxygen consumption during exercise in patients with angina pectoris. Circulation. 1978;57:549-56.

87. Moir D, Rickert WS, Levasseur G, Larose Y, Maertens $\mathrm{R}$, White $\mathrm{P}$, et al. A comparison of mainstream and sidestream marijuana and tobacco cigarette smoke produced under two machine smoking conditions. Chem Res Toxicol. 2008;21:494-502.

88. Johnstone RE, Lief PL, Kulp RA, Smith TC. Combination of delta 9-tetrahydrocannabinol with oxymorphone or pentobarbital. Anesthesiology. 1975;42:674-84.

89. Gorelick DA, Heishman SJ, Preston KL, Nelson RA, Moolchan ET, Huestis MA. The cannabinoid CB1 receptor antagonist rimonabant attenuates the hypotensive effect of smoked marijuana in male smokers. Am Heart J. 2006;151:754.e1-754.e5.

90. Pihl RO, Shea D, Caron P. The effect of marihuana intoxication on blood pressure. J Clin Psychol. 1978;34:569-70.

91. Mortensen SP, Damsgaard R, Dawson EA, Secher NH, GonzálezAlonso J. Restrictions in systemic and locomotor skeletal muscle perfusion, oxygen supply and $\mathrm{VO} 2$ during high-intensity wholebody exercise in humans. J Physiol. 2008;586:2621-35.

92. Roger VL, Pellikka PA, Oh JK, Miller FA, Seward JB, Tajik AJ. Stress echocardiography. Part I. Exercise echocardiography: techniques, implementation, clinical applications, and correlations. Mayo Clin Proc. 1995;70:5-15.

93. La Gerche A, Claessen G, Van De Bruaene A, Pattyn N, Van Cleemput J, Gewillig M, et al. Cardiac MRI: a new gold standard for ventricular volume quantification during high-intensity exercise. Circ Cardiovasc Imaging. 2013;6:329-38.

94. Geyer H, Caracciolo G, Abe H, Wilansky S, Carerj S, Gentile $\mathrm{F}$, et al. Assessment of myocardial mechanics using speckle 
tracking echocardiography: fundamentals and clinical applications. J Am Soc Echocardiogr. 2010;23:351-69.

95. Stöhr EJ, Shave RE, Baggish AL, Weiner RB. Left ventricular twist mechanics in the context of normal physiology and cardiovascular disease: a review of studies using speckle tracking echocardiography. Am J Physiol Circ Physiol. 2016;311:H633-44.

96. Khanji MY, Jensen MT, Kenawy AA, Raisi-estabragh Z, Paiva JM, Aung N, et al. Association between recreational cannabis use and cardiac structure and function. JACC Cardiovasc Imaging. 2020;13:886-8.

97. Cheung CP, Coates AM, Millar PJ, Burr JF. Habitual cannabis use is associated with altered cardiac mechanics and arterial stiffness, but not endothelial function in young healthy smokers. J Appl Physiol. 2021;130:660-70.

98. Bonz A, Laser M, Kullmer S, Kniesch S, Babin-Ebell J, Popp V, et al. Cannabinoids acting on CB1 receptors decrease contractile performance in human atrial muscle. J Cardiovasc Pharmacol. 2003;41:657-64.

99. Steffens S, Veillard NR, Arnaud C, Pelli G, Burger F, Staub C, et al. Low dose oral cannabinoid therapy reduces progression of atherosclerosis in mice. Nature. 2005;434:782-6.

100. Huestis MA, Gorelick DA, Heishman SJ, Preston KL, Nelson RA, Moolchan ET, et al. Blockade of effects of smoked marijuana by the CB1-selective cannabinoid receptor antagonist SR141716. Arch Gen Psychiatry. 2001;58:322-8.

101. Pletcher M, Vittinghoff E, Kalhan R, Richman J, Safford M, Sidney S, et al. Association between marijuana exposure and pulmonary function over 20 years. J Am Med Assoc. 2012;307:173-81.

102. Tashkin DP. Effects of marijuana smoking on the lung. Ann Am Thorac Soc. 2013;10:239-47.

103. Tashkin DP, Shapiro BJ, Frank IM. Acute pulmonary physiologic effects of smoked marijuana and oral delta-9-tetrahydrocannabinol in healthy young men. N Engl J Med. 1973;289:336-41.

104. Tashkin DP, Reiss S, Shapiro BJ, Calvarese B, Olsen JL, Lodge JW. Bronchial effects of aerosolized $\Delta 9$ tetrahydrocannabinol in healthy and asthmatic subjects. Am Rev Respir Dis. 1977;115:57-65.

105. Wolfarth B, Wuestenfeld JC, Kindermann W. Ergogenic effects of inhaled 32 -agonists in non-asthmatic athletes. Endocrinol Metab Clin North Am. 2010;39:75-87.

106. Wold-Anti Doping Agency (WADA). Prohibited List. World Anti-Doping. 2016. pp. 1-116.

107. Riiser A, Stensrud T, Stang J, Andersen LB. Can $\beta 2$-agonists have an ergogenic effect on strength, sprint or power performance? Systematic review and meta-analysis of RCTs. Br J Sports Med. 2020;54:1351-9.

108. Goodman S, Wadsworth E, Leos-Toro C, Hammond D. Prevalence and forms of cannabis use in legal vs. illegal recreational cannabis markets. Int J Drug Policy. 2020;102658:1-10.

109. Morales P, Reggio PH, Jagerovic N. An overview on medicinal chemistry of synthetic and natural derivatives of cannabidiol. Front Pharmacol. 2017;8:1-18.

110. McCartney D, Benson MJ, Desbrow B, Irwin C, Suraev A, McGregor IS. Cannabidiol and sports performance: a narrative review of relevant evidence and recommendations for future research. Sport Med. 2020;6:1-18.

111. WADA. Summary of major modifications and explanatory notes: substances and methods prohibited at all times. World Anti-Doping Agency. 2018. pp. 1-2.

112. Walsh NP, Halson SL, Sargent C, Roach GD, Nédélec M, Gupta L, et al. Sleep and the athlete: narrative review and 2021 expert consensus recommendations. Br J Sports Med. 2021;55:356-68.

113. Dunican IC, Walsh J, Higgins CC, Jones MJ, Maddison K, Caldwell JA, et al. Prevalence of sleep disorders and sleep problems in an elite super rugby union team. J Sports Sci. 2019;37:950-7.
114. Tuomilehto H, Vuorinen VP, Penttilä E, Kivimäki M, Vuorenmaa $M$, Venojärvi M, et al. Sleep of professional athletes: underexploited potential to improve health and performance. J Sports Sci. 2017:35:704-10.

115. Fullagar HHK, Duffield R, Skorski S, Coutts AJ, Julian R, Meyer T. Sleep and recovery in team sport: current sleep-related issues facing professional team-sport athletes. Int J Sports Physiol Perform. 2015;10:950-7.

116. Fullagar H, Skorski S, Duffield R, Meyer T. The effect of an acute sleep hygiene strategy following a late-night soccer match on recovery of players. Chronobiol Int. 2016;33:490-505.

117. Fowler PM, Knez W, Crowcroft S, Mendham AE, Miller J, Sargent $\mathrm{C}$, et al. Greater Effect of east versus west travel on jet lag, sleep, and team sport performance. Med Sci Sports Exerc. 2017:49:2548-61.

118. Erlacher D, Ehrlenspiel F, Adegbesan OA, El-Din HG. Sleep habits in German athletes before important competitions or games. J Sports Sci. 2011;29:859-66.

119. Lastella M, Lovell GP, Sargent C. Athletes' precompetitive sleep behaviour and its relationship with subsequent precompetitive mood and performance. Eur J Sport Sci. 2014;14:S123-30.

120. Sargent C, Halson S, Roach GD. Sleep or swim? Early-morning training severely restricts the amount of sleep obtained by elite swimmers. Eur J Sport Sci. 2014;14:S10-315.

121. Romyn G, Robey E, Dimmock JA, Halson SL, Peeling P. Sleep, anxiety and electronic device use by athletes in the training and competition environments. Eur J Sport Sci. 2016;16:301-8.

122. Shannon S, Opila-Lehman J. Effectiveness of cannabidiol oil for pediatric anxiety and insomnia as part of posttraumatic stress disorder: a case report. Perm J. 2016;20:108-11.

123. Chagas MHN, Eckeli AL, Zuardi AW, Pena-Pereira MA, Sobreira-Neto MA, Sobreira ET, et al. Cannabidiol can improve complex sleep-related behaviours associated with rapid eye movement sleep behaviour disorder in Parkinson's disease patients: a case series. J Clin Pharm Ther. 2014;39:564-6.

124. Carlini EA, Cunha JM. Hypnotic and antiepileptic effects of cannabidiol. J Clin Pharmacol. 1981;21:417S-427S.

125. Linares IMP, Guimaraes FS, Eckeli A, Crippa ACS, Zuardi AW, Souza JDS, et al. No acute effects of Cannabidiol on the sleepwake cycle of healthy subjects: a randomized, double-blind, placebo-controlled, crossover study. Front Pharmacol. 2018;9:1-8.

126. Owens DJ, Twist C, Cobley JN, Howatson G, Close GL. Exercise-induced muscle damage: what is it, what causes it and what are the nutritional solutions? Eur J Sport Sci. 2019;19:71-85.

127. Julian R, Page RM, Harper LD. The effect of fixture congestion on performance during professional male soccer match-play: a systematic critical review with meta-analysis. Sport Med. 2021;51:255-73.

128. Tsitsimpikou C, Jamurtas A, Fitch K, Papalexis P, Tsarouhas K. Medication use by athletes during the Athens 2004 Paralympic Games. Br J Sports Med. 2009;43:1062-6.

129. Bertolini A, Ottani A, Sandrini M. Dual acting anti-inflammatory drugs: A reappraisal. Pharmacol Res. 2001;44:437-50.

130. Devinsky O, Thiele EA, Wright S, Checketts D, Morrison $\mathrm{G}$, Dunayevich E, et al. Cannabidiol efficacy independent of clobazam: meta-analysis of four randomized controlled trials. Acta Neurol Scand. 2020;142:531-40.

131. Chesney E, Oliver D, Green A, Sovi S, Wilson J, Englund A, et al. Adverse effects of cannabidiol: a systematic review and meta-analysis of randomized clinical trials. Neuropsychopharmacology. 2020;2020:1-8.

132. Huestis MA, Solimini R, Pichini S, Pacifici R, Carlier J, Busardò FP. Cannabidiol adverse effects and toxicity. Curr Neuropharmacol. 2019;17:974-89. 
133. Mlost J, Bryk M, Starowicz K. Cannabidiol for pain treatment: focus on pharmacology and mechanism of action. Int J Mol Sci. 2020;21:1-22.

134. Naftali T, Mechulam R, Marii A, Gabay G, Stein A, Bronshtain $\mathrm{M}$, et al. Low-dose cannabidiol is safe but not effective in the treatment for Crohn's disease, a randomized controlled trial. Dig Dis Sci. 2017;62:1615-20.

135. Irving PM, Iqbal $\mathrm{T}$, Nwokolo $\mathrm{C}$, Subramanian $\mathrm{S}$, Bloom $\mathrm{S}$, Prasad N, et al. A randomized, double-blind, placebo-controlled, parallel-group, pilot study of cannabidiol-rich botanical extract in the symptomatic treatment of Ulcerative Colitis. Inflamm Bowel Dis. 2018;24:714-24.

136. Cochrane-Snyman KC, Cruz C, Morales J, Coles M. The effects of cannabidiol oil on noninvasive measures of muscle damage in men. Med Sci Sport Exerc. 2021;53:1460-72.

137. Isenmann E, Veit S, Diel P. Effects Of cannabidiol supplementation on the skeletal muscle regeneration after intensive resistance training. Med Sci Sport Exerc. 2020;52:766-766.

138. Karr JE, Areshenkoff CN, Garcia-Barrera MA. The neuropsychological outcomes of concussion: a systematic review of metaanalyses on the cognitive sequelae of mild traumatic brain injury. Neuropsychology. 2014;28:321-36.

139. Barth JT, Freeman JR, Broshek DK, Varney RN. Accelerationdeceleration sport-related concussion: the gravity of it all. J Athl Train. 2001;36:253-6.

140. Gardner AJ, Iverson GL, Williams WH, Baker S, Stanwell P. A systematic review and meta-analysis of concussion in Rugby Union. Sport Med. 2014;44:1717-31.

141. Gardner A, Iverson GL, Levi CR, Schofield PW, Kay-Lambkin F, Kohler RMN, et al. A systematic review of concussion in rugby league. Br J Sports Med. 2015;49:495-8.

142. Kerr ZY, Roos KG, Djoko A, Dalton SL, Broglio SP, Marshall $\mathrm{SW}$, et al. Epidemiologic measures for quantifying the incidence of concussion in national collegiate athletic association sports. $\mathrm{J}$ Athl Train. 2017;52:167-74.

143. Lessley DJ, Kent RW, Funk JR, Sherwood CP, Cormier JM, Crandall JR, et al. Video analysis of reported concussion events in the National Football League during the 2015-2016 and 20162017 seasons. Am J Sports Med. 2018;46:3502-10.

144. Bernick C, Hansen T, Ng W, Williams V, Goodman M, Nalepa B, et al. Concussion occurrence and recognition in professional boxing and MMA matches: toward a concussion protocol in combat sports. Phys Sportsmed. 2021;2021:1-7.

145. McCrory P, Meeuwisse WH, Aubry M, Cantu B, Dvořák J, Echemendia RJ, et al. Consensus statement on concussion in sport: the 4th International Conference on Concussion in Sport held in Zurich, November 2012. Br J Sports Med. 2013;2013:250-8.
146. Dean PJA, Sato JR, Vieira G, McNamara A, Sterr A. Long-term structural changes after mTBI and their relation to post-concussion symptoms. Brain Inj. 2015;29:1211-8.

147. Belardo C, Iannotta M, Boccella S, Rubino RC, Ricciardi F, Infantino R, et al. Oral cannabidiol prevents allodynia and neurological dysfunctions in a mouse model of mild traumatic brain injury. Front Pharmacol. 2019;10:352.

148. Pazos MR, Cinquina V, Gómez A, Layunta R, Santos M, Fernández-Ruiz J, et al. Cannabidiol administration after hypoxia-ischemia to newborn rats reduces long-term brain injury and restores neurobehavioral function. Neuropharmacology. 2012;63:776-83.

149. Pazos MR, Mohammed N, Lafuente H, Santos M, MartínezPinilla E, Moreno E, et al. Mechanisms of cannabidiol neuroprotection in hypoxic-ischemic newborn pigs: Role of 5HT1A and CB2 receptors. Neuropharmacology. 2013;71:282-91.

150. Lastres-Becker I, Molina-Holgado F, Ramos JA, Mechoulam R, Fernández-Ruiz J. Cannabinoids provide neuroprotection against 6-hydroxydopamine toxicity in vivo and in vitro: relevance to Parkinson's disease. Neurobiol Dis. 2005;19:96-107.

151. Carrier EJ, Auchampach JA, Hillard CJ. Inhibition of an equilibrative nucleoside transporter by cannabidiol: a mechanism of cannabinoid immunosuppression. Proc Natl Acad Sci USA. 2006;103:7895-900.

152. Nair A, Jacob S. A simple practice guide for dose conversion between animals and human. J Basic Clin Pharm. 2016;7:27.

153. Gurley BJ, Murphy TP, Gul W, Walker LA, ElSohly M. Content versus label claims in cannabidiol (CBD)-containing products obtained from commercial outlets in the state of Mississippi. J Diet Suppl. 2020;17:599-607.

154. Wong A, Montebello ME, Norberg MM, Rooney K, Lintzeris N, Bruno R, et al. Exercise increases plasma THC concentrations in regular cannabis users. Drug Alcohol Depend. 2013;133:763-7.

155. Gunasekaran N, Long LE, Dawson BL, Hansen GH, Richardson DP, Li KM, et al. Reintoxication: The release of fat-stored $\Delta$ 9tetrahydrocannabinol (THC) into blood is enhanced by food deprivation or ACTH exposure. Br J Pharmacol. 2009;158:1330-7.

156. Russo EB. The case for the entourage effect and conventional breeding of clinical cannabis: no "Strain", no gain. Front Plant Sci. 2019;9:1969.

157. Stout SM, Cimino NM. Exogenous cannabinoids as substrates, inhibitors, and inducers of human drug metabolizing enzymes: a systematic review. Drug Metab Rev. 2014;46:86-95.

158. Jiang R, Yamaori S, Takeda S, Yamamoto I, Watanabe K. Identification of cytochrome P450 enzymes responsible for metabolism of cannabidiol by human liver microsomes. Life Sci. 2011;89:165-70. 